\title{
7
}

\section{Criteria-oriented order allocation in a multisite production structure - A decision support instrument for the clothing industry}

\author{
U. Friemuth, Ph. von Wrede
}

Research Institute for Rationalisation and Operations Management

Pontdriesch 14/16, D-52062 Aachen, Phone ++ 49/241- 47705 - 0, Fax ++ 49/241-402401, e-mail:postmaster@fir-rwth-aachen.de

\section{PRODUCTION PLANNING IN A MULTISITE PRODUCTION STRUCTURE}

\subsection{Introduction}

The globalisation of production becomes more important even for small and medium sized companies. However, their motives for an international production are very different. One motive is the reduction of production costs by producing at low cost production sites. Other important reasons are e.g. by-passing certain political or juridical requirements and the advantage of favourable infrastructure and market conditions (Verret, 1993). 
The production at distributed locations leads to a higher production planning complexity in comparison to companies that produce only at one site. A special requirement in a multisite production structure is the allocation of a single production order to different available production sites. Therefore an assistance of the order allocation by a decision support instrument seems to be useful.

Due to an increased cost pressure and a high share of manual production processes, the clothing industry produces within a multisite production structure. By the example of the clothing industry the development of a decision support instrument will be demonstrated.

\subsection{Order allocation requirements by distributed sites}

The economical situation as well as the environment of companies with a multisite production structure defines typical requirements to the order allocation within distributed sites.

If the production is performed only at one company, necessary capacities exist only in this company. In this case, a capacity levelling is performed under identical planning conditions like equal labour costs. If external capacities are integrated in the production process, the complexity of the capacity levelling will increase. Additional to criteria like e.g. dates and quantities that have also to be considered by an internal capacity levelling, criteria like e.g. transport times, quota regimes or international laws have to be taken into account.

\subsection{Order allocation criteria}

The performance of a production order leads to different capacity demands for particular production steps. A variety of different criteria are necessary to choose appropriate capacities (Figure 1). The most important criterion is the capacity availability for a special period. The two criteria capacity and time are mainly used for the capacity levelling by production planning and control systems (Kernler, 1993). Especially in long term planning steps other aspects like e.g. the suitability of capacity for a special production order or a single machining step have to be considered. On the basis of criteria like e.g. technical equipment, production quality or required qualification the different capacities have to be checked if they are suitable for the processing of a single production process. In case of a positive review a capacity levelling on the basis of time and quantity is possible.

The capacity planning with international distributed sites leads to an enlargement of relevant allocation criteria. At first criteria have to be considered which ensue from the geographical distance between alternative production sites and the parent company. Criteria like e.g. transport times between the parent company and the production site have to be integrated in the allocation process. In most cases, the legal and organisational independence between the parent company and its 
production sites have also an effect on criteria like production surveillance or compliance with quality conditions.

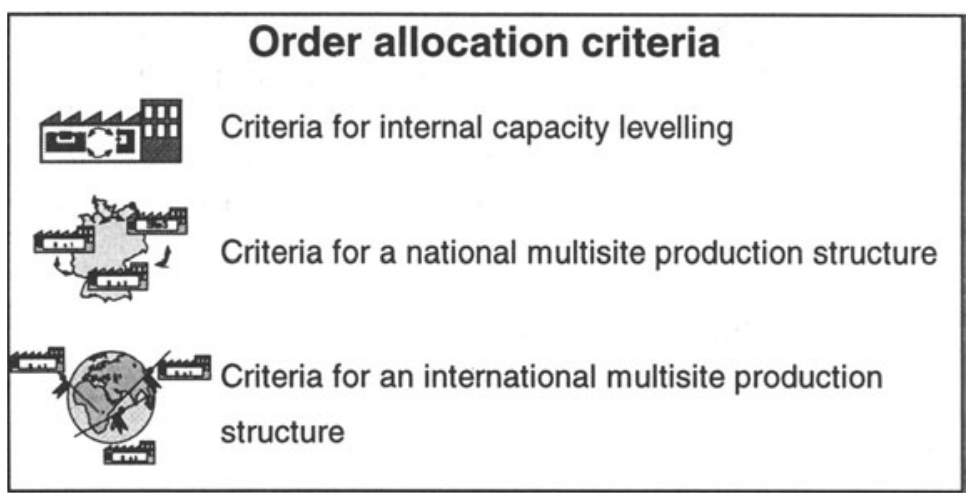

Figure 1 Allocation criteria.

The location of production sites outside the national borders results in a further group of allocation criteria. Allocations to production sites within the European Union require only very few additional criteria. Criteria like contrary agreements on working hours or different holidays have an impact on the allocation decision. Due to low labour costs a lot of production sites are located outside the European Union in East Europe, in North Africa and in south-east Asia. In this case criteria like e.g. customs regulations and international systems of trade become very important for an allocation decision.

\subsection{Definition of the allocation decision problem}

The criteria-oriented order allocation has to attain different objectives. Whereas minimised costs still represent the main target other objectives like better production quality and customer oriented logistic gain an increasing importance.

A maximised achievement of each objective at the same time is not feasible. An improved order allocation has to deal with several competing objectives. There exists e.g. a conflict between an improved logistic performance and low costs.

A criteria-oriented order allocation to international distributed production sites has to consider a variety of contrary allocation criteria. Different criteria characteristics express the requirements of a single order. The measurability structures the allocation criteria (Zimmermann, 1991). Hence order allocations have to consider criteria with different kinds of measurability.

The aim of the described decision problem is an improved achievement of most relevant allocation objectives. In many cases the allocation criteria are very similar. But the criteria relevance can vary enormously. Therefore the criteria relevance has a large impact on the allocation decision. The allocation criteria must be weighted according to their relevance. 
The planner has in general all relevant information. If special information deficits occur in most cases he can obtain the necessary information very quickly. A decision under certainty can be assumed.

A production order is characterised by different order requirements. These requirements lead to a requirement profile (Figure 2). In contrast to the production planning in a singlesite company the requirement profile in a multisite production structure has to be adapted and enlarged.

The requirement profile has to be compared with the profiles of the different production sites. The production site profile contains all allocation relevant characteristics of a single production site. Sites in different countries and regions differ according to country specific conditions. The profile regards all relevant conditions. The order allocation process needs a complete order requirement profile as well as a production site profile. The fit of an order requirement profile to the site profiles of international distributed production sites describes the suitability of an order to a certain site.

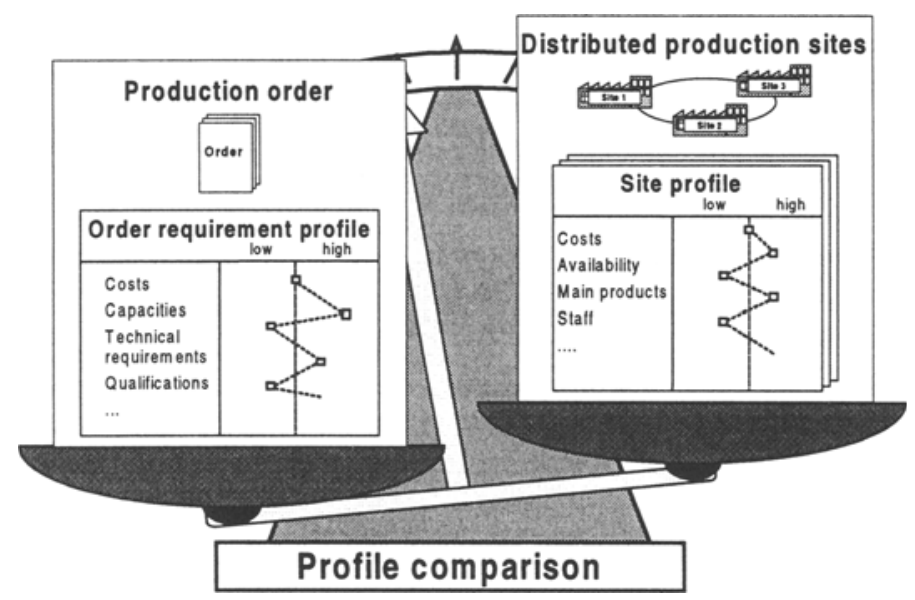

Figure 2: Profile comparison.

The comparison of both profiles has to be assisted in an efficient way. Therefore an instrument has been developed that enables the production planner to allocate an order to the most suitable site. Basis of the instrument is a set of analytical derived criteria combined with an allocation strategy that bases on the multicriteria-analysis.

\subsection{Allocation strategy}

The multi-criteria-analysis methods only partially fulfil the requirements of the production planning with distributed production sites. In a decision tree all relevant criteria are arranged in a tree structure. The planner checks the fulfilment of every aspiration level for each possible solution. Solutions that fulfil any aspiration level 
are banned from further considerations. A balance between calculation effort and decision quality offers the Analytical Hierarchy Process-method (AHP-method). The AHP-method solves even complex decision problems. In addition to this the experience and the valuation of the planner can be integrated in the decision process. The instrument for an criteria-oriented order allocation to distributed production sites uses the decision tree as well as the AHP-method. The developed allocation strategy is therefore based on both methods. The strategy combines the specific advantages and disadvantages of each method.

\section{CONVERSION IN A PRACTICE-ORIENTED INSTRUMENT}

\subsection{Approach of the instrument}

The approach of the instrument to assist the order allocation to distributed production sites is characterised by different stages (Figure 3). The approach itself and the assistance of each stage guarantees a structured allocation decision process.

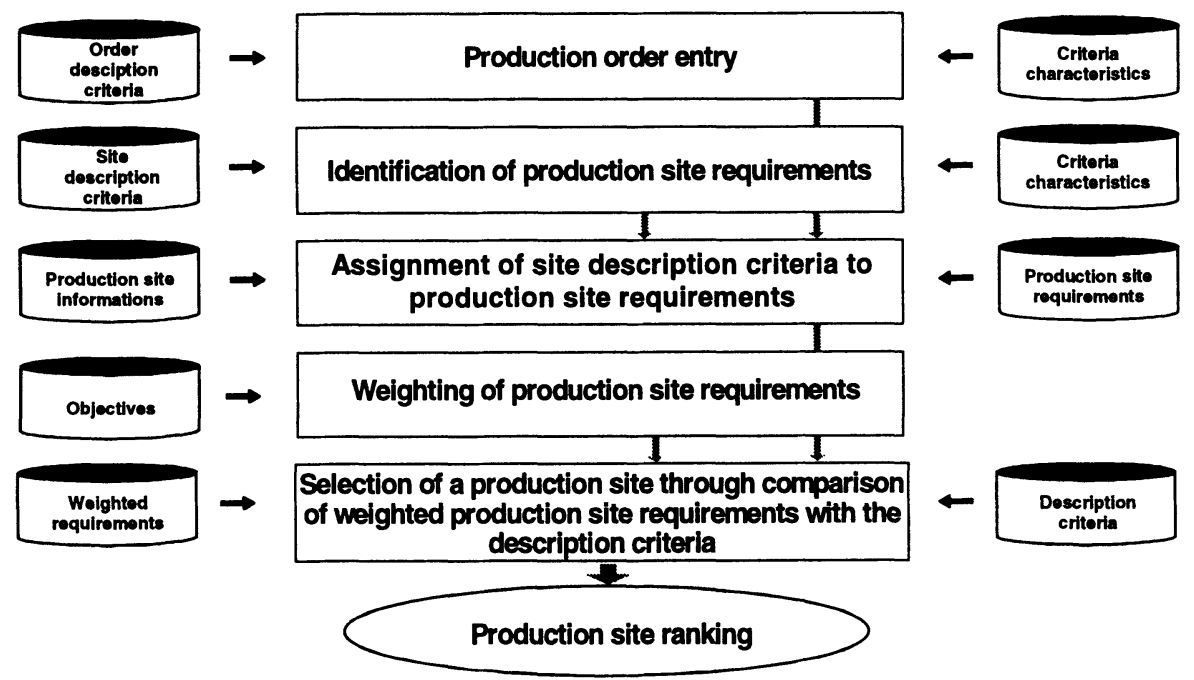

Figure 3 Planning approach in a multisite production structure.

Starting point of the order allocation to a production site is the order itself. Often the order recording fails in covering allocation-relevant information. Therefore a standardised order recording is essential. All information that is necessary for an efficient order allocation has to be pooled. The orders are recorded by order description criteria. The criteria can vary from company to company. Each order is described entirely. This builds the necessary data-basis for a criteria-oriented order allocation. 
On the basis of an enlarged order description production site requirements can be identified. These site requirements define the necessary standards for a site performance. Finally the site requirements characterise the allocation criteria.

The order allocation needs adequate information about the distributed sites. Often exist only unstructured and incomplete site information. A structured documentation that enables any person to get the relevant information that is essential for an criteria-oriented order allocation. In the instrument the site situation is described by site description criteria.

The identification and adaptation of site information are more or less independent from an order. Even in case of a short term order a wide range of important site information is available due to the identified site description criteria. Only some essential information has to be updated in short time when a special order is recorded. Information to secure in short time are e.g. free capacities or delivery times.

A consideration of all site requirements at the same time needs a weighting of each site requirement. The instrument guarantees a realistic weighting of site requirements by a objective hierarchy.

In case of a concrete order entry the identified and weighted site requirements are compared with the site description criteria. A first rating founds on the identified must-criteria. This rating bases on a decision tree. A second rating compares all site requirements with the relevant site description criteria.

The result is a ranking of alternative production sites. Finally the planner is free to choose the suitable site according to this ranking. Considering calculated fulfilment scores of each site he finally decides where the order will be processed.

\subsection{Assistance of allocation stages}

The object hierarchy arranges detailed objectives on different levels (Figure 4). On the basis of a top objective the planner structures the objectives in different objective groups on varying levels according to the allocation problem. This guarantees a flexible adaptation to each allocation problem. The hierarchy of objectives covers several levels. The objectives on the lowest level represent the order requirements to the production sites. The different order requirements can be summed in an order requirement profile. The profile has to be compared with the different production site profiles. 


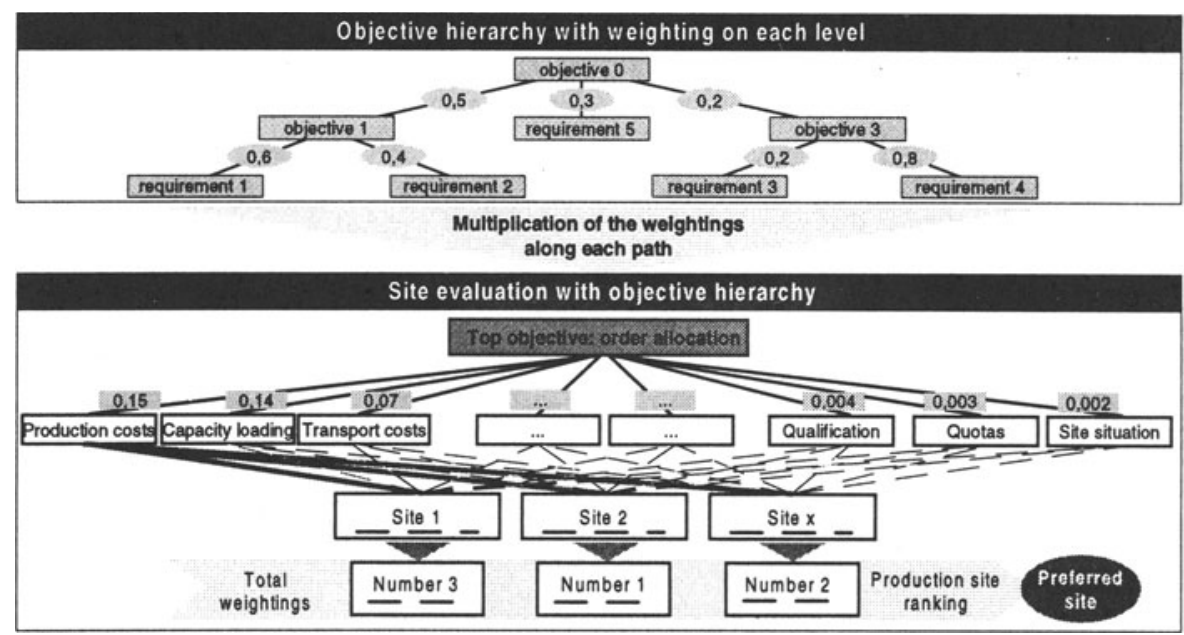

Figure 4 Order allocation with the AHP-method.

\section{ORDER ALLOCATION IN THE CLOTHING INDUSTRY}

\subsection{Problem description for the clothing industry}

Especially the clothing industry in industrialised countries has to deal with certain requirements of international markets. It has to deal with a strong import competition and largely saturated markets. The enormous competitive pressure within the clothing industry, in combination with shorter product life cycles and a higher variety of stylish garments complicates the situation of the clothing industry. A growing share of stylish garments, shorter developing cycles, a declining share of fixed orders from the clothing retailers and shorter delivery times lead to special requirements for the clothing industry (Hurks, 1993).

The trend to produce at different and distributed production sites offers the clothing industry on the one side enormous cost saving opportunities especially by low labour costs (Rigby, 1993). On the other side the co-ordination expense grows due to production at distributed locations. To keep the conversion charge low, the co-ordination has to be supported efficiently. Especially the allocation of production orders to distributed sites requires an criteria-oriented approach (Friemuth, 1997; Thierry, 1995).

\subsection{Structure of the clothing production process}

To get an idea of the production structure in the clothing industry the clothing production processes and the essential information and materials flows will be explained briefly (Figure 5). 


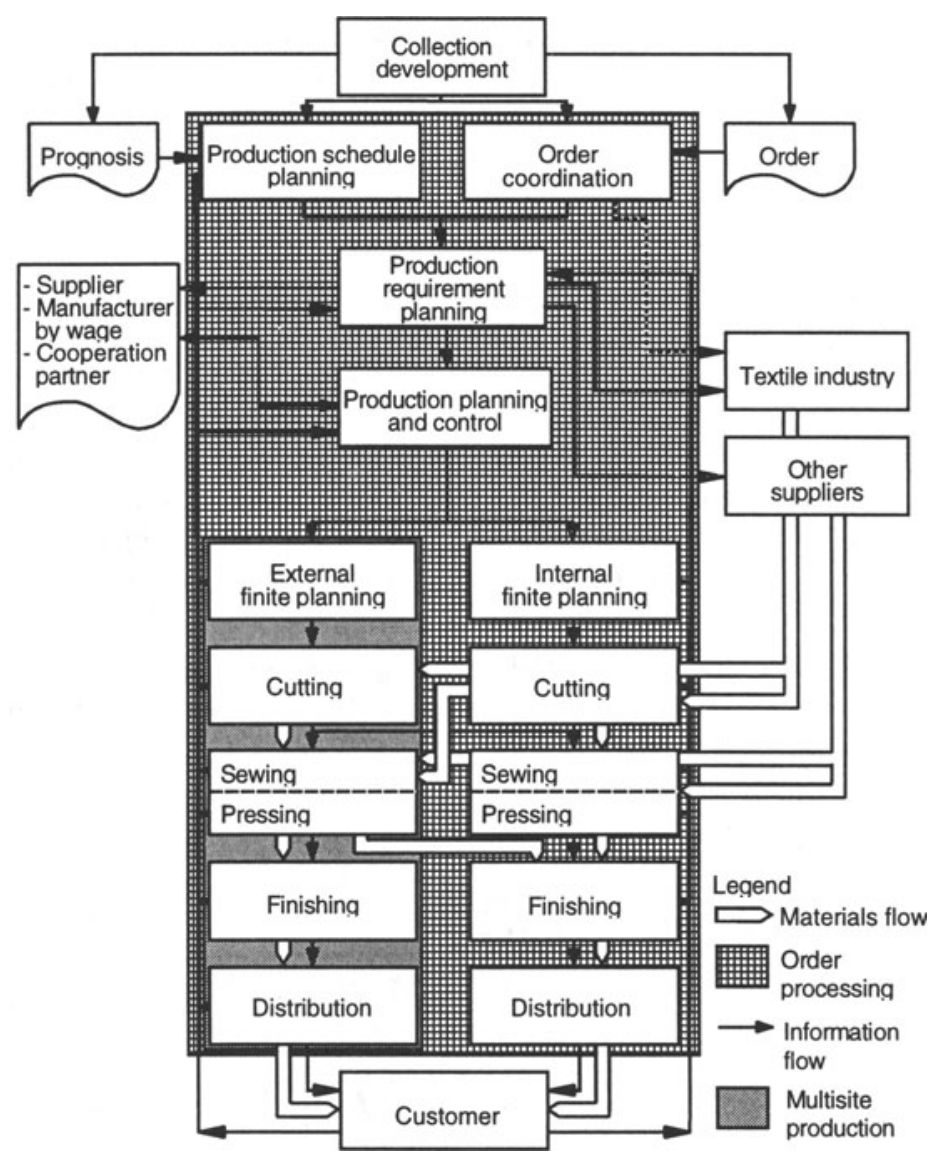

Figure 5 Information and materials flow in a clothing company.

The product of a clothing company is the collection. The collection consists of several different garment models. Especially clothing companies that work on market segments with very stylish garments develop and offer their collections on a seasonal basis. The incoming customer orders are handled in the order coordination. On the other hand garments are produced to stock. In case of stock production, production schedule plans are planed periodically. The order coordination as well as the production program planning follows the production requirement planning. At this planning stage a detailed purchase order for the textile suppliers is possible. Necessary external capacities at co-operation partners can be ordered. The production planning and control finally decides which order will be allocated to a certain production site.

The finite planning is done at the distributed production sites. The actual production starts with the cutting from textile raw materials according to special patterns. At the next step, the sewing presents the core process of the clothing 
production. In different sewing stages the final garment will be made. During and after the sewing process it is necessary to press the garments to gain certain shapes. The final production process is the finishing. The garment will get a marketable state here. The finished garments are delivered in most cases from a centralised stock at the clothing company.

\subsection{Order allocation on different planning steps}

The site requirement weighting depends on the planning step. In the same way the comparison of the site requirements and the site description criteria rely on the planning step. In each planning step the significance of a site requirement can change. Whereas long-term planning steps consider a large number of different order allocation criteria like e.g. site appearance, the short term planning steps reduce the criteria to important ones like e.g. delivery dates and quantities. The instrument contains groups of representative site requirements. These requirements are of value for the whole clothing industry. Figure 6 shows on the example of a clothing company with a seasonal job order manufacture criteria for each planning step.

\section{Requirements for seasonal job order manufacturer}

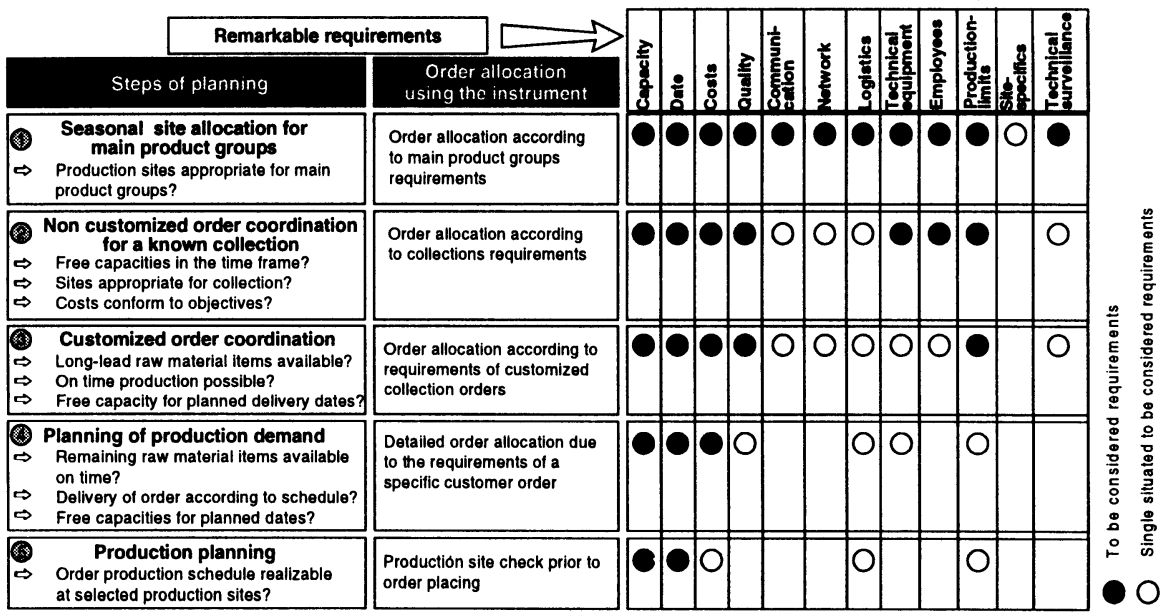

Figure 6 Order allocation criteria for each planning step.

In the first planning step, the seasonal order allocation for main product groups, the orders are allocated according to the requirements of the main product groups. Because of the long-range planning period and because of the large number of alternative production sites all identified site requirements are integrated in the planning process. In the following steps the requirements of the order are more detailed. Corresponding the significance of few site requirements become more 
important. Because of the order allocation in the previous planning steps the allocation decision is made on the basis of a limited number of feasible production sites. The order allocation bases on the lower planning steps only on few significant requirements. The order allocation in the final planning step relies in most cases on the required dates and capacities. The remaining production sites in this planning step fulfil all relevant site requirements. The fulfilment of these requirements has been checked in the previous planning steps. In this way an efficient limitation according to the order processing type and to the planning step is possible.

The application of the developed instrument for each planning step allows the consideration of all significant site requirements. Even in the short term planning steps all requirements are considered without a testing of each requirement in each planning step.

\subsection{Evaluation of the instrument}

The developed instrument covers the defined requirements. The selected allocation strategy and the transfer into a practice-oriented instrument for different planning steps allows an efficient order allocation. The whole allocation process becomes transparent and reconstructable. Relevant allocation criteria are considered by the instrument and the company strategy is integrated in the allocation process. The structured instrument approach and the possibility to adapt previous weightings relieves the planner for more complex allocation decisions. Finally the developed instrument can be integrated into existing data processing solutions.

The usability of the instrument has been tested in different German clothing companies. Especially the structured approach and the assistance of inexperienced employees have been judged positively. An interested software company that is specialised in the clothing industry sees the integration of the instrument as an addon to their existing production planning and control system.

Furthermore the developed instrument seems to be adaptable to the requirements of other industries dealing with a high share of production processes in a multisite production structure.

\section{REFERENCES}

Friemuth, U. and von Wrede, Ph. (1997) Produktionsplanung bei verteilten Standorten: nicht nur Lösung auf Knopfdruck, Bekleidung \& wear, Volume 49, Number 8, 32-33.

Kernler, H. (1993) PPS der 3. Generation. Hüthig Buch Verlag, Heidelberg.

Rigby, D. (1993) Patterns of success: what can the little dragons learn from successful textile companies in developed countries, in Asia and World Textiles (ed. The Textile Institute), Manchester. 
Thierry, C., Besnard, P., Ghattas, D. and Bel, G. (1995) Multi-site planning: Non flexible production units and set-up time treatment, in 1995 INRIA/IEEE Symposium on Emerging Technologies and Factory Automation, Paris, 262269.

Verret, R. (1993) Textile plant location strategy in a global competitive environment, in Asia and World Textiles (ed. The Textile Institute), Manchester.

Zimmermann, H.J. and Gutsche, L. (1991) Multi-Criteria Analyse. Springer Verlag, Berlin.

\section{BIOGRAPHY}

Dipl.-Ing. Dipl.-Wirt. Ing. Ulrich Friemuth is head of the logistics department at the Research Institute of Operations Management (FIR) at Aachen University of Technology.

Dipl.-Ing. Dipl.-Wirt. Ing. Philip von Wrede is scientific engineer in the logistics department at FIR.

\section{ACKNOWLEDGEMENT}

The project „Optimisation of the production planning with distributed sites in the clothing industry“ has been financed by the „Arbeitsgemeinschaft industrieller Forschungsvereinigungen AiF e. V." (consortium of industrial research institutes) with the number $10.335 \mathrm{~N}$ funded by the "Bundesministerium für Wirtschaft" (German ministry of trade and industry). 